\title{
Sobre la iconografía de San Sebastián y una escultura del Círculo de Alejo de Vahía en la Iglesia Parroquial de Fontiveros (Ávila)
}

\author{
Sonia CABALLERO ESCAMILLA \\ Universidad de Salamanca
}

\begin{abstract}
RESUMEN. El culto a los santos en la Edad Media fue uno de los aspectos primordiales de las prácticas religiosas y devocionales de la época. En este caso analizamos el culto a San Sebastián y el desarrollo de su iconografía, apoyándonos para ello en una talla conservada en la iglesia parroquial de Fontiveros que atribuimos al círculo del escultor Alejo de Vahía.

Palabras clave: santos, devoción, espiritualidad, caballero, Ecce Homo.

RÉSumÉ. Au Moyen-Âge, le culte aux saints a été l'un des aspects plus importants des pratiques religieuses et dévotionelles de l'époque médiévale. En ce cas, nous étudions le culte à Saint Sébastien et le développement de son iconographie, nous nous basons sur una taille conservée à l'église de Fontiveros que nous attribuisons au circle du sculpteur Alejo de Vahía.

Mots clés: saints, dévotion, spiritualité, chevalier, Ecce Homo.
\end{abstract}

La creencia en los poderes taumatúrgicos de los santos y la protección que éstos dispensaban en momentos tan importantes como el de la muerte en la mentalidad medieval, tuvo como consecuencia la aparición de textos que daban cuenta de la vida, muerte y milagros de tan insignes personajes. Textos hagiográficos cuyo uso variaba dependiendo del marco en que fueran utilizados. Podían formar

\footnotetext{
${ }^{1}$ En la actualidad, Becaria de la Fundación del Patrimonio Histórico de Castilla y León en el Departamento de Historia del Arte de la Universidad de Salamanca.
}

parte de la devoción privada en las manos de un fiel pero podían ser el instrumento principal de lecturas ritualizadas y "representadas" en el marco devocional de una comunidad religiosa ${ }^{2}$.

\section{-}

${ }^{2}$ P. M. CÁTEDRA, “Lectura femenina en el claustro (España, siglos XIV-XVI)", D. DE COURCELLES y C. VAL JULIÁN, Des femmes et des livres: France et Espagne, XIV $e_{-}$ XVII e siècle, París, 1999, pp. 7-53; Idem, "Liturgia, poesía y la renovación del teatro medieval", Actas del XIII Congreso de la Asociación Internacional de Hispanistas, (Madrid, 6-11 de julio de 1998), I, Madrid, 2000, pp. 3-28; Idem, Bibliotecas y lecturas de mujeres. Siglo XVI, Salamanca, 2004; Idem, Liturgia, poesía y teatro en la Edad Media, Madrid, 2005. 
La nueva espiritualidad basada en una lectura íntima de los textos y una emotiva vivencia de los pasajes pasionales se apoyaba en obras de arte que recreaban con todo lujo de detalles la vida y martirio de los personajes sagrados ${ }^{3}$. Esculturas y pinturas de Cristo, la Virgen y los santos poblaban los altares de los oratorios privados y las capillas de los templos para fijar la devoción de los fieles que las consideraban una vía privilegiada para entrar en comunicación con la divinidad.

El extraordinario culto a los santos que se dio, de una manera más acentuada, al final de la Edad Media tenía como fin la petición de la intercesión en momentos de enfermedad o muerte. En este sentido, San Sebastián llegó a ser uno de los santos más venerados en la Edad Media, como mártir y como protector ante la peste, desde que Pablo Diácono explicara en su Historia Longobardorum que en el 680 había librado a Roma de esta epidemia ${ }^{4}$. Esta circunstancia se hizo extensible a la ciudad de Pavía lo que provocó una invocación popular cada vez que existía una plaga.

\footnotetext{
${ }^{3}$ Existe una gran cantidad de estudios sobre devoción y arte. Sin ánimo de ser exhaustivos, véase HARBISON, "Visions and meditations in early Flemish painting", Simiolus, 15, 1985, pp. 87-118; J. HAMBURGUER, "The visual and the visionary: the image in late medieval monastic devotions", Bulletin Monumental, 1990, pp. 161-182; S. RINGBOM, Les images de dévotion XII -XVe siécle, París, 1995, p. 101; R. SÁNCHEZ AMEIJEIRAS, "Devociones e imágenes medievales en la provincia eclesiástica de Mondoñedo", Estudios Mindonienses, no 15 , 1999, pp. 375-409; J. MOLINA I Figueras, “Contemplar, meditar, rezar. Función y uso de las imágenes en torno a 1500", Catálogo de la exposición El arte en Cataluña y los reinos hispanos en tiempos de Carlos I, Barcelona, 19-12-2000 a 4-3-2001, p. 98; F. ESPAÑOL BERTRÁN, “Les imatges marianes: prototips, rèpliques I devoció", Lambard, XV (2002-2003), 2003, pp. 87-109.

${ }^{4}$ J. YARZA LUACES, Alejo de Vahía, mestre d'imatges, Quaderns del Museo Frederic Marès, Exposicions 6, Barcelona, 2001, p. 326.
}

Según la leyenda, San Sebastián sirvió como centurión a los emperadores Diocleciano y Maximiano y tras su conversión al cristianismo fue condenado a morir asaeteado con flechas. La categoría social del personaje hizo que durante la Edad Media adquiriera tintes de caballero medieval, de ahí que se extendiera un modelo iconográfico en el que se le figuraba ataviado con lujosas vestimentas y atributos, como un grueso collar pendiendo de su cuello (Lám. 1). Este tipo gozó de un gran éxito en la Corona de Aragón durante el S. XV, como se deduce de su presencia en las obras de importantes pintores como Miquel Nadal, entre otros. Sin embargo, no fue ésta su única variante iconográfica sino que, al menos en la Corona de Castilla, tuvo un mayor predicamento aquella en la que se enfatizaban las condiciones del martirio al que fue sometido: desnudo, tapado con un paño de pureza y con el cuerpo cubierto de flechas. Pero, incluso dentro de esta tipología, se establecen ligeras diferencias, como la colocación de los brazos hacia atrás o bien hacia delante, el hecho de distinguirle con un tocado o, por el contrario, presentarle con la cabeza descubierta. Ya Francesca Español relacionó este tipo iconográfico con un tema que se iba a convertir en uno de los éxitos devocionales de finales de la Edad Media, el Ecce Homo, por medio del cual Cristo era presentado al pueblo después de ser azotado, medio desnudo, cubierto con el paño de pureza y las manos atadas delante, sobre el vientre ${ }^{5}$. La aplicación del modelo de Cristo Varón de Dolores a San Sebastián le convirtió en una pieza devocional. Ya no estamos ante una representación narrativa en la que se puede ver el martirio ubicado en un paisaje o bien la figura del santo revestido de lujosas vestimentas, ahora nos

\footnotetext{
-

${ }^{5}$ Véanse los comentarios de Francesca Español en Finarte España Subastas: Pintura Antigua, siglos XIX y XX. Muebles y Objetos de Colección, Subasta PM-59, Madrid, 2000, p. 16.
} 
encontramos frente a frente ante el sufrimiento, acorde con la manera de vivir la religión en este momento último de la Edad Media.

Pues bien, en la iglesia parroquial de Fontiveros se conserva una talla de San Sebastián, junto con otras piezas de diversas épocas, en una especie de museo improvisado en una de las capillas del lado del Evangelio del templo. Pero, probablemente, su emplazamiento original fue otro, como comentaremos. Acostumbrados a apreciar tallas y pinturas sobre pedestales, amontonadas en las salas de los museos o expuestas en las capillas de los templos, destinadas a la contemplación estética por parte de los visitantes-turistas que acuden a la iglesia, olvidamos la verdadera finalidad que tuvieron y los usos y funciones que cumplieron ${ }^{6}$.

San Sebastián aparece desnudo, cubierto con un perizonium y con las manos atadas delante de su cuerpo (Lám. 2). De este modo, recuerda la iconografía de Cristo en la flagelación, buscada, por otra parte, conscientemente. Incluso el árbol al que fue atado se ha sustituido por una columna situada tras él, con lo que se acentúa aún más el carácter cristológico del mismo ${ }^{7}$. Se trata de una tipología utilizada ya a principios del S. XV, como se manifiesta en un libro de plegarias realizado en Gueldre para la duquesa María $^{8}$, aunque en este

\section{-}

${ }^{6}$ S. CABALlero ESCAMILLA, "Función y recepción de las artes plásticas en el S. XV", Norba Arte, vol. XXVI, 2006, pp. 19-31.

${ }^{7}$ Se trata de un detalle de gusto muy hispánico con varios ejemplos en la pintura del S. XV. Por señalar uno de ellos, véase la predela de un retablo de la Colegiata de Daroca. D. MARTENS, "Autour d'une oeuvre inédite du Maître de la Légenda de Sainte Lucie. Quelques observations sur un type rare de l'iconographie de Saint Sébastien à la fin du Moyen Âge", Jaarboek, 1993, pp. 47-79.

${ }^{8}$ Catálogo de la exposición Saint-Sébastien. Rituels et figures, Musée National des Arts et Traditions Populaires, París, 1983-1984. № 21. caso la columna se sitúa delante y no detrás. Debió de ser una fórmula propia del Norte de Europa pero que se extendería por la Península Ibérica enriquecida con otros elementos. Alejo de Vahía creó un modelo que gozó del favor del público, por cuanto se difundió por varias de las actuales provincias de Palencia, Valladolid y, como vemos, Ávila9 ${ }^{9}$. Se trata de una tipología próxima a la del Cristo de la flagelación y que se resume en el ejemplar fontivereño: desnudo con un perizonium cubriéndole las caderas, con las manos atadas por delante -en otras ocasiones por detrás-, atado a un árbol o columna y distinguido con un tocado de caballero y un collar sobre el pecho, los dos atributos que nos recuerdan su alta condición social. Una fórmula muy extendida en la escultura, no así en la pintura donde se prefirió el modelo ejecutado por Roger van der Weyden en su retablo de Beaune, presentando a San Sebastián desnudo y con los brazos atados a la espalda. Un motivo que coincide también con la iconografía italiana, probable origen del $\operatorname{mismo}^{10}$.

Centrándonos en la obra de Fontiveros, coincide genéricamente con el prototipo creado por Alejo de Vahía en el que se reúnen todos los elementos dispersos hasta entonces: de un tamaño inferior al natural (102 cm.), tiene una anatomía sumaria en la que no se marcan ni las costillas ni el esternón, a diferencia de otras obras como el conservado en el Museo Marés de Barcelo-

\footnotetext{
${ }^{9}$ Joaquín Yarza ha destacado las esculturas de las iglesias de San Andrés de Arbejal en Palencia, Santa Lucía de Collazos de Boeda o el que formó parte del retablo de San Esteban de Portillo así como el de Bustillo de Chaves, ambos en Valladolid, como algunos de los ejemplos próximos al fontivereño, sobre todo el último de ellos. J. YARZA, Alejo de Vahía....op.cit., p. 326.

${ }^{10}$ Un San Sebastián de este tipo, anterior a 1450, fue representado por Piero della Francesca en el Políptico de la Cofradía de la Misericordia. Vid. D. MARTENS, “Autour d'une oeuvre inédite...", op.cit., pp. 4779.
} 
na (Lám. 3) ${ }^{11}$. El tipo de tocado corresponde a una variedad de bonete citada en la documentación como gorra de media vuelta. Aunque surgió muy a finales del S. XV fue especialmente usada en el S. XVI ${ }^{12}$; se llevaba con melena larga y rizada, tal y como vemos en la escultura de la iglesia abulense, por lo que podemos fecharla a comienzos de la decimosexta centuria. Existen múltiples ejemplos de San Sebastián tocado con un bonete o gorra en xilografías del S. XV ${ }^{13}$, de la misma manera que, en esa misma técnica, unas veces aparece atado a un árbol y otras a una columna (Lám. 4). Conocemos el poder difusor del grabado y seguramente debemos a este medio la expansión de fórmulas y motivos existentes en la iconografía de San Sebastián, tanto en soporte pictórico como escultórico. Sin embargo, la combinación de todos esos elementos, bonete, collar y columna, sólo se dio a partir de la obra de Alejo de Vahía.

Mientras que el tocado está presente en otras representaciones del santo, como ya hemos visto, la combinación con el collar viene a ser un unicum en su iconografía ${ }^{14}$. Sí aparece en ejemplos en los que se presenta ataviado al modo de un caballero, como es

\footnotetext{
${ }^{11}$ Vid. ficha correspondiente en J. YARZA LUACES, Alejo de Vahía....op.cit. p. 203.

${ }^{12}$ C. BERNIS, Trajes y modas en la España de los Reyes Católicos II. Los Hombres, Madrid, 1979, p. 92.

${ }^{13}$ En el Museo del Louvre se conservan varias xilografías de este tipo. Vid. A. BLUM, Les Primitifs de la Gravure sur Bois. Étude historique et catalogue Des xilographies du Musée du Louvre, París, 1956. También en Munich, Vid. Katalog von Dieter Kuhrmann Die Frühzeit des Holzschnottes, Staatloche Graphische Gamnilungen, Munich, 1970. Agradecemos esta información al profesor Didier Martens, de la Universidad Libre de Bruselas.

${ }^{14}$ Uno de los que presentan todos los elementos que vemos en el ejemplar abulense, es decir, bonete, collar, manos atadas por delante y perizonium, es el San Sebastián del Palacio Arzobispal de Valladolid, procedente del retablo de San Esteban del Portillo. Una obra que se ha considerado como producto de taller. C. J. ARA GIL, En torno al escultor Alejo de Vahía (1490-1510), Valladolid, 1974, p. 67.
}

el caso del retablo atribuido al taller de Jaime Huguet conservado en la capilla de San Sebastián y Santa Tecla de la catedral de Barcelona. En la tabla principal, San Sebastián se viste con indumentaria de gran riqueza, tocado y collar en función de su alta categoría social. El tipo de gorra elegida era usada por miembros de importantes clases sociales y lo mismo se puede decir del collar, que le distinguiría como un alto cargo en la cohorte de los emperadores romanos y su posición como hombre de confianza de los mismos. Sin embargo, no existen ejemplos conocidos en los que se disponga el collar sobre el torso desnudo, salvo en la órbita de Alejo de Vahía y sus seguidores.

El rostro es ovalado, con los ojos ligeramente arqueados y las cejas finas, no faltando los mechones de pelo característicos sobre la frente. El torso está apenas trabajado y una de las piernas avanza más que la otra dibujando un ángulo, es decir, algunos de los rasgos típicos de las figuras de Alejo. Sin embargo, la forma de concebir las facciones está alejada del maestro, sobre todo en lo que se refiere a la nariz y los labios, extremadamente finos, sin el típico gesto del labio inferior a manera de ligera sonrisa que caracteriza su producción. En definitiva, unos detalles muy sutiles que nos llevan a pensar, como se ha establecido en otros casos similares, que se trata de una obra de su círculo en la que se han seguido los patrones del maestro, quizás, con su participación activa ${ }^{15}$. Así fue manifestado por el profesor Yarza en el caso de un San

\footnotetext{
${ }^{15}$ La diferencia de calidad entre algunas obras y el elevado número de esculturas que se pueden adscribir a su entorno ha llevado a pensar que la mayor parte fueron realizadas por su taller. F. J. MONTALVO MARTín, "Dos nuevas obras del círculo de Alejo de Vahía", Boletín del Museo e Instituto <<Camón Aznar >>, no XCIII, 2004, pp. 97-102.
} 
Sebastián perteneciente a una colección particular madrileña ${ }^{16}$.

Uno de los primeros autores que reparó en la escultura fue Gómez Moreno quien la calificó como de estilo flamenco "de mérito y extrañamente engalanado con collar y gorra"17. Fue Joaquín Yarza quien la relacionó con Alejo de Vahía en $1987^{18}$, sin embargo, en nuestra opinión, habría que adscribirlo a un colaborador que sigue de cerca el modelo del maestro en los primeros años del S. XVI pero con ligeras diferencias que lo definen como obra de su entorno.

Con el transcurrir de los años, el carácter icónico de San Sebastián se acentúa al prescindir del resto de los personajes que conformaban la escena, acentuado más si cabe en la escultura. San Sebastián se presenta ante el fiel como objeto de veneración. El culto a los santos estaba vinculado a su poder de intercesión en el momento de la muerte pero también a la protección dispensada en vida frente a distintas enfermedades. En el caso de San Sebastián se le consideraba como el protector de la peste debido a uno de los milagros narrados en la Leyenda Dorada, según el cual, una epidemia cesó en Pavía después de dedicar un altar a San Sebastián. Su poder taumatúrgico y su perseverancia en la fe en Jesucristo favorecieron la dedicación de iglesias y altares dentro y fuera de nuestras fronteras. $\mathrm{Mu}$ chas de sus representaciones se encargaban para beneficiarse de sus poderes curativos, como se ha sugerido en el caso de una de las xilografías conservadas en la Biblioteca Nacional de Viena ${ }^{19}$. Pero no era la única

${ }^{16}$ J. YARZA LUACES, Alejo de Vahía...op.cit., p. 327.

${ }^{17}$ M. GÓMEZ MORENO, Catálogo de la provincia de Ávila, vol. I, Ávila, 2002 (2ª ed.), p. 283.

${ }^{18}$ J. YARZA LUACES, “Definición y ambigüedad del tardogótico palentino: escultura", Actas del I Congreso de Historia de Palencia, tomo I, Valladolid, 1987, p. 41.

${ }^{19}$ A. BLuM, Les Primitifs...op.cit., $\mathrm{n}$ o 18 . razón del éxito de esta iconografía. Su propio carácter de mártir asesinado por su defensa de la religión cristiana le presentaba como exemplum de tenacidad, fe en Jesucristo y del triunfo sobre las heterodoxias. Por este motivo tuvo un gran protagonismo en los sermones de los predicadores ${ }^{20}$, origen probable del éxito de esta iconografía a finales de la Edad Media.

Desconocemos las circunstancias que motivaron el encargo de este San Sebastián así como el nombre del cliente pero, dado el nivel social de las familias que se enterraron en la parroquial de Fontiveros, como dan cuenta los emblemas heráldicos que se han conservado, existe la posibilidad de que una de ellas estuviera tras el encargo destinado a centrar un pequeño altar devocional. Sin embargo, Alejo de Vahía y su taller trabajaron frecuentemente para parroquias, por lo que no debemos desechar tampoco la posibilidad de que constituyera los restos de un retablo desmontado y desaparecido en la actualidad o bien que fuera una obra independiente adquirida por la propia parroquia para un pequeño altar de una capilla. Así ocurrió en otros casos, como el grupo de Santa Ana Triple de la catedral de Palencia, encargada por un canónigo como una talla independiente ${ }^{21}$. Sea como fuere, el San Sebastián de la iglesia de Fontiveros viene a ser una muestra más del éxito de un modelo creado en el entorno de Alejo de Vahía y difundido por varias zonas de la geografía peninsular, prueba indudable de su éxito.

El culto medieval a los santos repercutió en la producción artística, incre-

\footnotetext{
${ }^{20}$ Por poner un ejemplo, San Vicente Ferrer lo citaba junto con otros santos, como Santa Catalina, como ejemplo a seguir dentro de la corriente antijudaica del momento. El texto completo del sermón se puede consultar en P. M. CÁTEDRA, Sermón, sociedad y literatura en la Edad Media. San Vicente Ferrer en Castilla (14111412), Salamanca, 1994, p. 191.

${ }^{21}$ J. YARZA LUACES, Alejo de Vahía....op.cit., p. 253.
} 
mentándose el número de tallas y retablos de carácter hagiográfico, en los que se veneraba desde los santos tradicionales a los santos de reciente canonización. Todos ellos eran utilizados como ejemplo de conducta, como protectores ante las enfermedades e intercesores en el momento de la muerte. Constituyeron verdaderas ymagines en el momento en que se gestaron pero, aparte de su valor histórico como documentos que atestiguan las actitudes de una sociedad en materia devocional y espiritual, constituyeron auténticos vehículos de transmisión de modelos foráneos, como es el caso. Un escultor tardogótico y de procedencia norteuropea, Alejo de Vahía, y su círculo,crearon en torno a la figura de San Sebastián, un nuevo tipo iconográfico que reunía en uno sólo los elementos importantes de su vida y martirio, el rango caballeresco en el tocado y el collar y su carácter como mártir mediante las flechas dispersas por su cuerpo desnudo. Pero no sólo eso sino que, acorde con la espiritualidad de finales de la Edad Media, crearon un icono destinado a la veneración, acentuado, más si cabe, por el paralelismo que se estableció con el propio Cristo. El resultado es uno de los modelos iconográficos más originales de la Edad Media y, en definitiva, el reflejo del sentimiento religioso de una época ${ }^{22}$.

${ }^{22}$ Este trabajo forma parte de uno de los capítulos de mi Tesis Doctoral, Las artes plásticas del S. XV en Ávila, defendida el 4 de septiembre de 2007 en la Facultad de Geografía e Historia de la Universidad de Salamanca. Por ello, quisiera aprovechar la ocasión para agradecer a mi directora de tesis $\mathrm{D}^{\mathrm{a}}$ Lucía Lahoz, Profesora Titular de Historia del Arte de la Universidad de Salamanca, su espíritu crítico y las sugerencias, siempre atinadas, que me proporciona. 


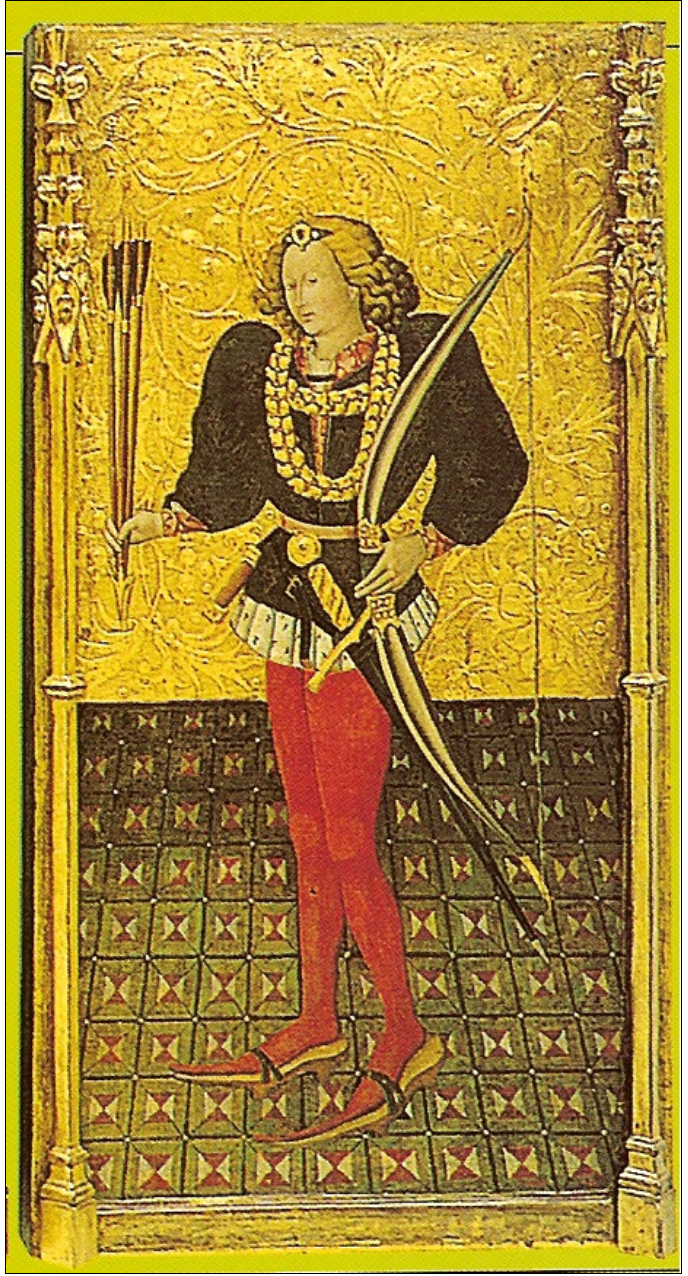

- Lám. 1. Jaume Ferrer, "San Sebastián”, Retablo dedicado a San Jerónimo, San Martín de Tours y San Sebastián, h. 1445-1455, Museo Nacional de Arte de Cataluña, Barcelona (Fuente: AA.VV., Guía visual. Arte Gótico, Barcelona, 2005, p. 31.). Detalle de la figura 4 (cliché IRPA, Bruselas).

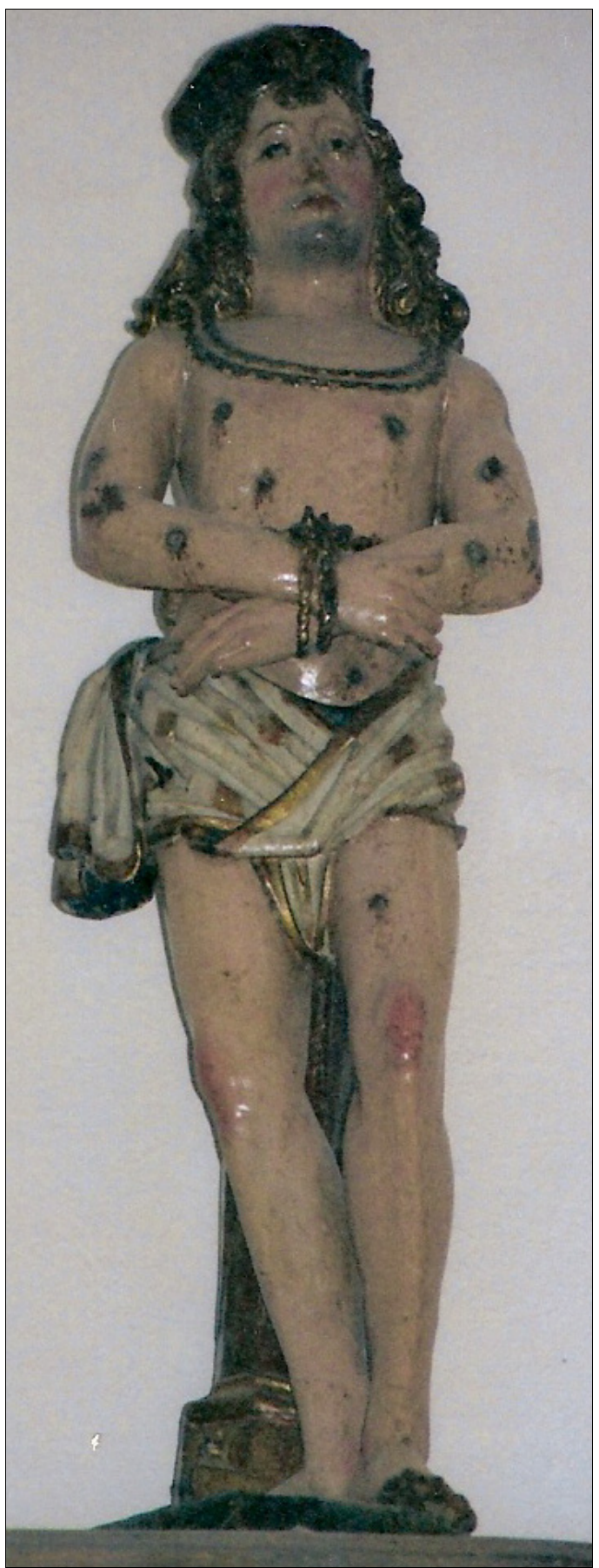

- Lám. 2. Círculo de Alejo de Vahía, “San Sebastián", Iglesia parroquial de Fontiveros (Foto: Sonia Caballero Escamilla). 


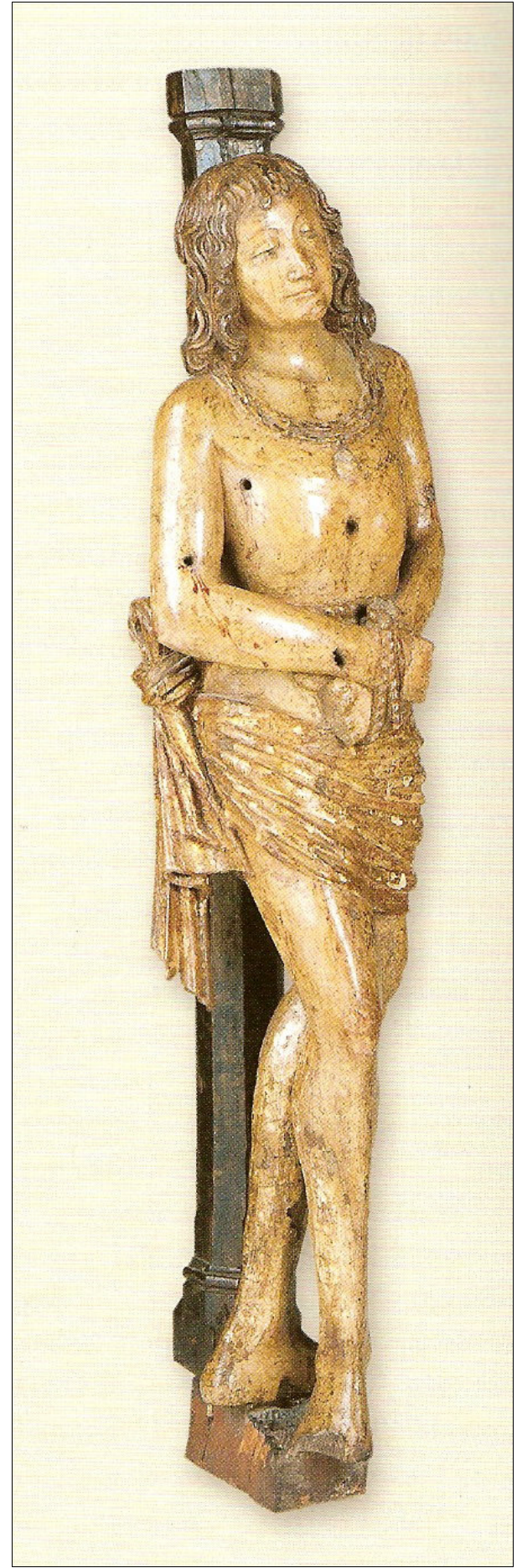

- Lám. 3. Alejo de Vahía y taller, "San Sebastián", Colección particular de Madrid (Fuente: J. Yarza Luaces, Alejo de Vahía, mestre d'imatges, Quaderns del Museo Frederic Marès, Exposicions 6, Barcelona, 2001, p. 172).

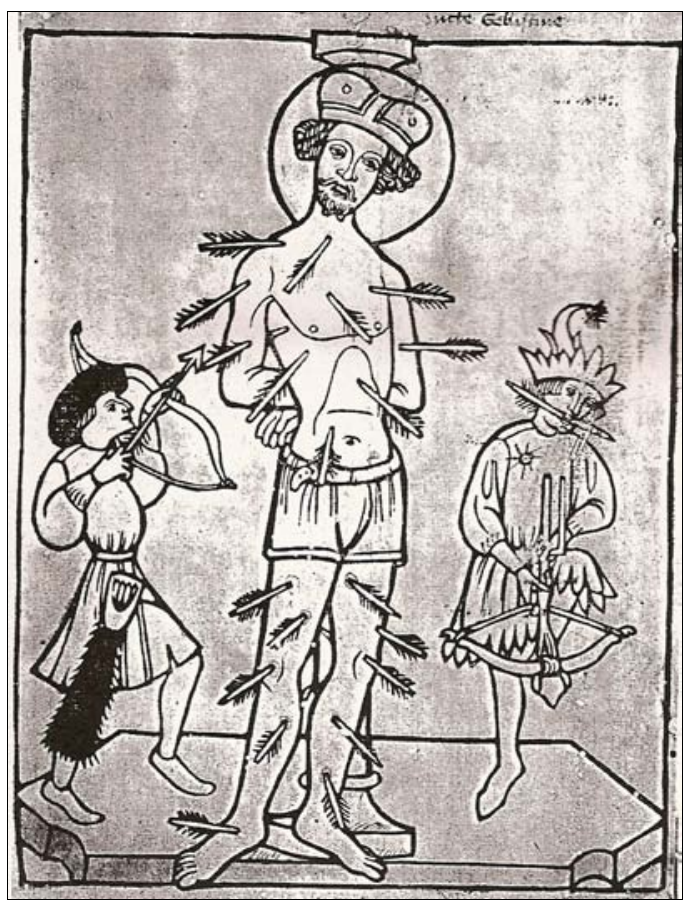

- Lám. 4. “San Sebastián”, xilografía, (Fuente: Katalog von Dieter Kuhrmann, Die Frühzeit des Holzschnottes, Staatloche Graphische Gamnilungen, Munich, 1970, no 8). 